This document is the accepted manuscript version of the following article:

Y. S. Ko, F. A. Nüesch, D. M. Opris, Charge generation by ultra-stretchable elastomeric electrets,

J. Mater. Chem. C, 2017, 5, 1826-1835

DOI: http://doi.org/10.1039/C6TC04956G

\title{
Charge generation by ultra-stretchable elastomeric electrets
}

\begin{abstract}
Yee Song Ko, ${ }^{a, b}$ Frank A. Nüesch, ${ }^{a, b}$ and Dorina M. Opris ${ }^{a}{ }^{*}$
Novel piezoelectric elastomers are synthesized and their long term stability and piezoelectric properties are investigated. They are thin film composites of specially designed polymer nanoparticles with high glass transition temperatures $\left(T_{g}\right)$ and side groups with large permanent dipoles, which are embedded in chemically crosslinked polydimethylsiloxane matrices. To obtain a piezoelectric material, the initially randomly oriented polar groups in the nanoparticles are poled in a strong electric field while the film is heated above the $T_{g}$ of the nanoparticles. Under these conditions the polar groups orient in the direction of the electric field and the achieved orientation is subsequently frozen-in by cooling the material back to room temperature. A permanent polarization responsible for the piezoelectricity is induced in the elastomers. All composites are elastic and can be strained up to $600 \%$. The lateral piezoelectric coefficient $d_{31}$ of the composites are found to first decrease over a period of several days before ultimately stabilizing. The largest $d_{31}$ value obtained, $12.1 \mathrm{pC} \mathrm{N}^{-1}$, is comparable to commercially available materials which are not elastic. Two composites exhibit promising thermal stability at $50{ }^{\circ} \mathrm{C}$ and generate a maxim of $2.5 \mathrm{~V}$ when strained. The novel elastic electret materials described in this paper are likely to find application as stretchable sensors, soft electronics, transducers and energy harvesters. Another important aspect of this work is the abundantly available combinations of elastic matrices and high $T_{g}$ polar polymers, which will allow the creation of elastic electrets with tailor-made properties in the future.
\end{abstract}

\section{Introduction}

Electrets are materials which are charged, either with a monocharge, opposing charges on both sides of the material or by an internal polarization. They are ubiquitous in many of today's applications, be it microphones, household filters or radiation sensors, ${ }^{1-5}$ with the most well-known material polyvinylidendifluoride (PVDF) found in many existing sensors and transducers due to its piezoelectric properties. ${ }^{6-9}$ Internal polarization is a prerequisite for piezoelectricity in a material. ${ }^{10}$ The change in polarization, when the material is mechanically stressed, is responsible for the generated current. Traditional piezoelectric electret materials are flexible, but lack elasticity which is fast becoming a requirement for their integration in emerging soft technologies, such as flexible and wearable devices, ${ }^{11,12}$ implantable devices ${ }^{13}$ and other biomedical applications. ${ }^{14,15}$ Research in this direction was already done as far back as 1991 by modifying crosslinked polydimethylsiloxane (PDMS) with mesogenic polar side groups, ${ }^{16}$ for which recently a piezoelectric coefficient under compression $\left(d_{33}\right)$ of $20 \mathrm{p} \mathrm{CN}^{-1}$ was achieved, ${ }^{21,22}$ but the performance of such materials under strain has not been evaluated. Elastomer-ceramic composites have been tested, such as composites containing barium titanate ${ }^{17}$ or a recent nanocomposite with lead magnesium-lead titanate (PMN-PT) in PDMS, which showed promise in producing large currents when strained. ${ }^{18}$ Other approaches are also actively considered, such as composites of monolithic, mesoporous PVDF filled with PDMS, ${ }^{19}$ or charged void electrets using PDMS with a precisely manufactured microstructure. ${ }^{20}$ For all the above mentioned works, polysiloxanes were used as matrix due to their excellent mechanical properties at different temperatures and frequencies, as well as easy chemical modification and crosslinking.

This work relies on the recently published concept of novel elastic electret composites based on purely organic components. ${ }^{23}$ The composites consist of specially designed copolymer nanoparticles dispersed in chemically crosslinked PDMS matrices. Said copolymers are composed of repeating units of methyl methacrylate and methacrylate modified with a side group with a large dipole moment. The composites are processed in thin films which are poled in an electric field above the glass transition temperature $\left(T_{g}\right)$ of the nanoparticles and cooled to room temperature with the electric field still on. This allows for the freezing of the aligned polar moieties in the high $T_{g}$ polymer. A schematic representation of the poling procedure and the mechanism for piezoelectricity in elastic electrets is shown in Fig. 1. The fillers are well-known polymers in nonlinear optics (NLO). ${ }^{22}$ Such polymers have large dipoles which can be poled in the same manner as just described, however, they normally have a low piezoelectric sensitivity due to their mechanical stiffness. A library of proven high polarization materials already exists to be used as filler materials which can be combined with different elastic matrices. In the previous work a copolymer of methyl methacrylate and a methacrylate modified with a Disperse Red 1 side group was used in form of nanoparticles as filler in a silicone matrix. Impedance spectroscopy and thermally stimulated depolarization current measurements were used to prove that a permanent polarization responsible for the piezoelectricity can be induced in the elastomer. The piezoelectric properties under compression $\left(d_{33}\right)$ at different pre-forces were investigated. ${ }^{23} \mathrm{~A}$ piezoelectric coefficient $d_{33}$ of $26.7 \mathrm{p} \mathrm{CN}^{-1}$ for the poled composite was found.

A unique merit of an elastic piezoelectric is its piezoelectric response to large lateral strains. The present paper presents data 
on the lateral piezoelectric coefficient $\left(d_{31}\right)$ at different strain levels, of the original composite and two additional novel elastic composite materials based on the same concept, as well as their thermal stability. In particular, the effect of matrix and filler on the composite performance is studied. Evidence is given that the matrix-NLO polymer concept is indeed very general.
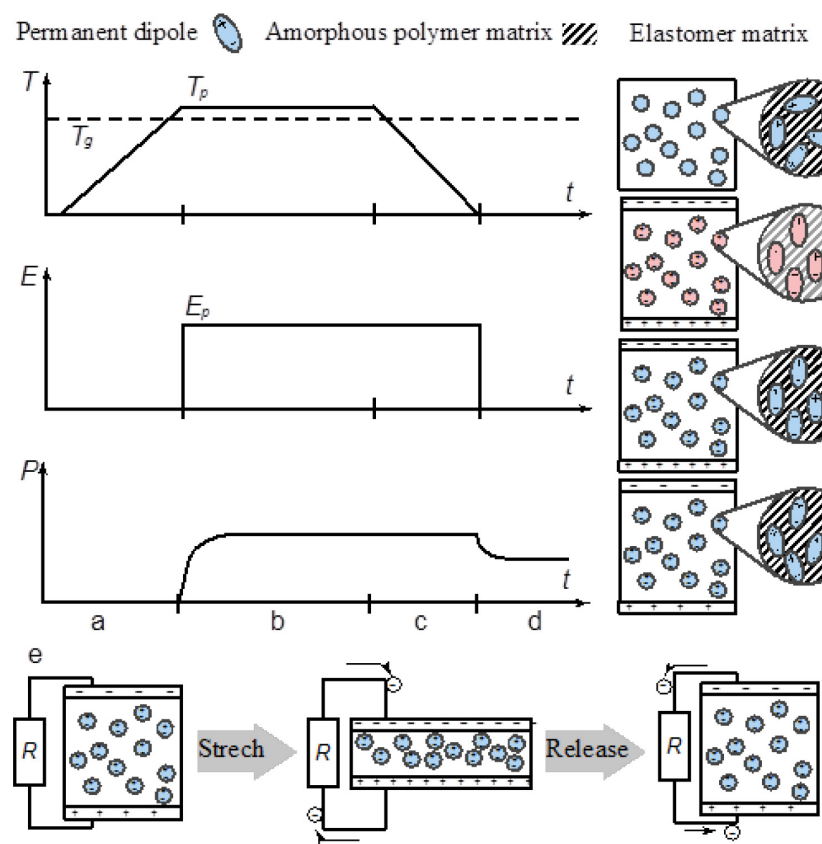

Fig. 1 Temperature- $(T)$, electric field- $(E)$ and sample polarization$(P)$ profile during a typical poling procedure and the schematic representation of the molecular dipoles. (a) The dipoles are first randomly oriented while the sample is heated. (b) At the poling temperature $T_{p}$ the poling field $E_{p}$ is turned on and the dipoles orient. (c) Once the dipoles are oriented, the temperature is lowered back to room temperature. Because the field is still on, the dipoles do not relax. (d) At room temperature the field is switched off and the dipoles relax slightly, but because of their low mobility in the amorphous matrix, some polarization is retained. (e) The dipole density changes upon dimensional changes of the material caused by stretching. A current flow can be detected as the charges on the material surface shift to the other side to compensate for the resulting polarization change.<smiles>CCN(CCOC(=O)C(C)(C)C)c1ccc(/N=N/c2ccc([N+](=O)[O-])cc2)cc1</smiles><smiles>COC(=O)CC(C)(C)C(=O)OCCN(C)c1ccc([N+](=O)[O-])cc1</smiles>

PMMA-co-NAMA

Scheme 1 Molecular structure of PMMA-co-DR1MA and PMMA-coNAMA.

\section{Results and discussion}

Two different fillers were used, both of them are copolymers of methyl methacrylate and methacrylate modified with a side group with a large dipole moment. The dipoles were 4-[ethyl (2-hydroxyethyl) amino]-4-nitrobenzene, usually called Disperse Red 1 (DR1), and 4-nitroaniline (NA) respectively. For the sake of better understanding, the copolymers were abbreviated to PMMA-co-DR1MA and PMMA-co-NAMA and the chemical structure of both copolymers can be seen in Scheme 1. DR1 is known for its large dipole moment $\mu$ of 7.5 $9.5 \mathrm{D},{ }^{25}$ while 4-nitroaniline has a respectable $\mu$ of $6 \mathrm{D}^{26}$ The synthesis and characterization of PMMA-Co-DR1MA with 50 mol\% DR1MA was described in another publication, ${ }^{23}$ while PMMA-Co-NAMA was prepared by free radical polymerization as discussed in the experimental section.

Table 1 Dipole fraction, molecular weight $\left(M_{w}\right)$, polydispersity index (PDI), glass transition temperature $\left(T_{g}\right)$, particle diameter $\left(d_{\text {part }}\right)$, and relaxation strength $(\Delta \varepsilon)$ of the filler copolymers.

\begin{tabular}{|c|c|c|c|c|c|c|}
\hline \multirow{2}{*}{ Copolymer } & Dipole fraction & $M_{w}$ & PDI & $T_{g}$ & $d_{\text {part }}$ & $\Delta \varepsilon$ \\
\hline & [NMR, \%] & {$\left[\mathrm{GPC}, \mathrm{g} \mathrm{mol}^{-1}\right]$} & [GPC] & {$\left[\mathrm{DSC},{ }^{\circ} \mathrm{C}\right]$} & {$[\mathrm{nm}]$} & $@ 140^{\circ} \mathrm{C}$ \\
\hline PMMA-Co-NAMA & 68 & $25^{\prime} 900$ & 1.59 & 94 & $57 \pm 17$ & 20.6 \\
\hline PMMA-co-DR1MA & 52 & $17^{\prime} 000$ & 2.1 & 125 & $60 \pm 15$ & 16.3 \\
\hline
\end{tabular}




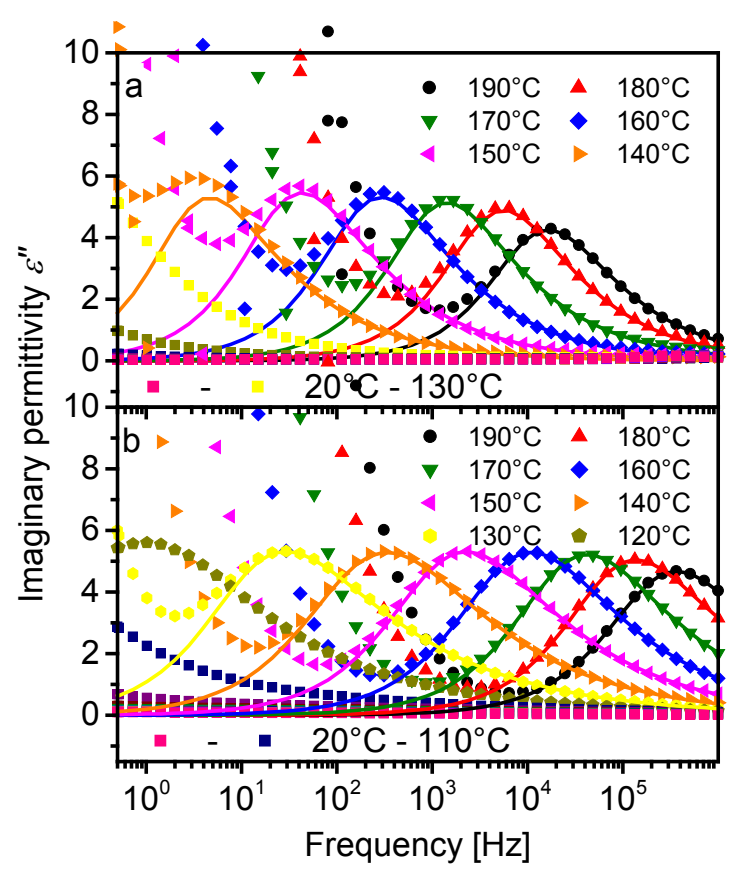

Fig. 2 Imaginary permittivity of the PMMA-co-DR1MA (a) and PMMA-Co-NAMA (b). The measurements are represented by dots; the $\mathrm{HN}$-fit is represented by lines.

The newly synthesized copolymer, PMMA-co-NAMA was thoroughly characterized. ${ }^{1} \mathrm{H}-\mathrm{NMR}$ shows that PMMA-coNAMA has been successfully synthesized and contains about $68 \%$ NAMA repeating units (Fig. S1 and Fig. S2 in the SI). Gel permeation chromatography (GPC) shows, that the copolymer has a molecular weight of $25^{\prime} 900 \mathrm{~g} \mathrm{~mol}^{-1}$ with a PDI of 1.59 (Fig. S3 in the $\mathrm{SI}$ ) and according to differential scanning calorimetry (DSC) (Fig. S4 in the SI) the $T_{g}$ actually decreased to $94{ }^{\circ} \mathrm{C}$ when compared to pure PMMA, which has a $T_{g}$ of 105 ${ }^{\circ} \mathrm{C} .{ }^{27} \mathrm{~A}$ low $T_{g}$ is usually detrimental to thermally poled structures and will lead to relaxation of the dipoles into a randomly oriented state because the matrix is insufficient, as exemplified by the low $T_{g}$, to stabilize the dipoles. ${ }^{28,29}$ These values are compared to PMMA-co-DR1MA in Table 1. Impedance spectroscopy was used to investigate the dipole relaxation characteristics and the reported data of PMMA-CoDR1MA ${ }^{23}$ are compared to those of PMMA-co-NAMA (Fig. 2). The features of both copolymers are very similar, showing one pronounced relaxation near their respective $T_{g}$.

Further information could be extracted by fitting the data above $130{ }^{\circ} \mathrm{C}$ to the Havriliak-Negami (HN) equation ${ }^{30}$

$\varepsilon^{*}=\varepsilon_{\infty}+i \frac{\sigma}{\varepsilon_{0} \omega}+\sum \frac{\Delta \varepsilon_{n}}{\left\{1+\left(i \omega \tau_{n}\right)^{\left.1-\alpha_{n}\right\}^{\beta_{n}}}\right.}$

where $\varepsilon^{*}$ is the relative permittivity, $\varepsilon_{\infty}$ its high frequency limit, $\sigma$ the dc-conductivity, and $\varepsilon_{0}$ the vacuum permittivity. The sum (running over the index $\mathrm{n}$ ) includes polarization contributions from different independent processes. $\Delta \varepsilon_{n}$ and $\tau_{n}$ are the relaxation strengths and characteristic times and the parameters $\alpha_{n}$ and $B_{n}$ describe the width and asymmetry of the corresponding dielectric loss peak. The $\mathrm{HN}$ equation is frequently used to describe the impedance spectrum of polymers. ${ }^{31-33}$ Data above $T_{g}$ could easily be fitted and the complete set of fit parameters and a figure of the real permittivity is available in the SI (Table S1-S4 and Fig. S5 in SI). The most pertinent parameter at present is the $\Delta \varepsilon$ of the dipole relaxation process, which enables the estimation of the sample polarization after poling via $^{34}$

$P_{\text {Theo }}=\varepsilon_{0} \Delta \varepsilon(T) E_{P}$

where $P_{\text {Theo }}$ is the theoretical polarization, $\Delta \varepsilon(T)$ the relaxation strength at the poling temperature and $E_{p}$ the poling field. It must be mentioned, that the $\Delta \varepsilon$ at the poling temperature of $120{ }^{\circ} \mathrm{C}$ should be used in this analysis, but because the measured frequency range was not low enough to resolve the static permittivity at this temperature, the value at $140{ }^{\circ} \mathrm{C}$ for PMMA-Co-DR1 and $130{ }^{\circ} \mathrm{C}$ for PMMA-Co-NAMA was taken as the next best approximation. The relaxation strengths of the copolymers are quite similar, with a slightly higher value of 20.6 for PMMA-Co-NAMA at $140{ }^{\circ} \mathrm{C}$ and of 19.9 for PMMA-CoDR1.

Nanoprecipitation was utilized to obtain the copolymers in particulate form (Fig. $3 a$ and b). The particle size after nanoprecipitation was investigated using SEM and shows that both copolymers can be processed into spherical nanoparticles which were around $60 \mathrm{~nm}$ diameter in size and can be confirmed by dynamic light scattering (Fig. S6). After collection and drying, the particles were dispersed in cyclohexane via tip sonication, followed by addition of PDMS. The mixture could then be blade casted to produce composite thin films. The exact procedure is described in the experimental section. As matrices, PDMS with two different molecular weights were chosen, one having a molecular weight of $139^{\prime} 000 \mathrm{~g} \mathrm{~mol}^{-1}$, which will be referred to as the low molecular weight matrix, and the other one $692^{\prime} 000 \mathrm{~g} \mathrm{~mol}^{-1}$, the high molecular weight matrix, to produce a total of three different composites. By using a higher molecular weight PDMS it should be possible to improve the performance of the composite by increasing the strain at break and lowering the elastic modulus. The composition of the three composites is summarized in Table 2. They were named as $X(y, z)$, where $X$ represents the polar side group of the copolymer filler (DR1 or NA), y represents the wt\% of the filler particles, and $z$ represents different silicone matrices used, i.e. I is for the lower molar mass and $\mathrm{h}$ for the high molar mass PDMS. Composite DR1 $(33, \mathrm{I})$ contained 33 wt\% PMMA-co-DR1MA particles in a low molecular weight matrix, composite DR1 $(40, h)$ contained $40 \mathrm{wt} \%$ PMMA-coDR1MA particles in a high molecular weight matrix and composite $\mathrm{NA}(33, \mathrm{~h})$ contained 33 wt\% PMMA-co-NAMA particles in a high molecular weight matrix. The synthesis and characterization of composite DR1 $(33,1)$ was described by Ko et. al. and we use it here as reference material to be able to show the achieved progress with the new materials. ${ }^{23}$ 
Table 2 Composition of the tested materials.

\begin{tabular}{|c|c|c|c|c|}
\hline \multicolumn{2}{|c|}{ Composite $^{a}$} & \multirow{2}{*}{$\frac{\text { DR1 }(33, \mathrm{I})}{\mathrm{DR} 1 \mathrm{MA}}$} & \multirow{2}{*}{$\begin{array}{c}\text { DR1 }(40, \mathrm{~h}) \\
\text { DR1MA }\end{array}$} & \multirow{2}{*}{$\frac{N A(33, h)}{\text { NAMA }}$} \\
\hline Filler & Dipole & & & \\
\hline & [\%] & 33 & 40 & 33 \\
\hline PDMS $M_{w}$ & {$\left[\mathrm{~g} \mathrm{~mol}^{-1}\right]$} & $139^{\prime} 000$ & $692^{\prime} 000$ & $692^{\prime} 000$ \\
\hline
\end{tabular}

${ }^{\mathrm{a}}$ For all composites $100 \mu \mathrm{l}$ of crosslinker to $1 \mathrm{~g}$ PDMS was added.

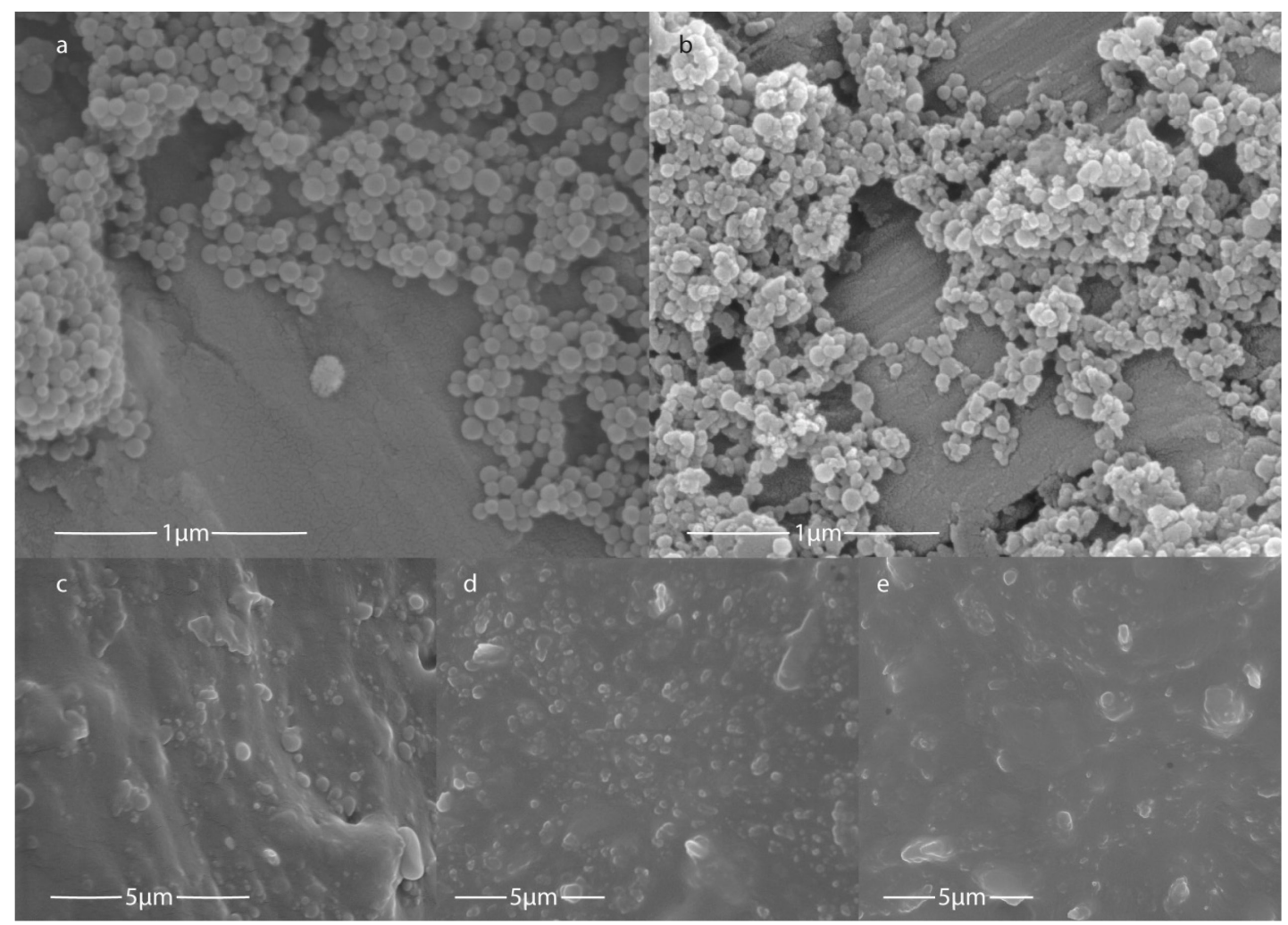

Fig. 3 SEM images of PMMA-co-DR1MA particles (a), PMMA-co-NAMA particles (b) as well as the composites DR1(33,l) (c), DR1(44,h) (d) and $\mathrm{NA}(33, \mathrm{~h})(\mathrm{e})$.

All composites were elastic and the obtained free standing films were typically $40 \mu \mathrm{m}$ thick. The properties of the composites in their unpoled state were investigated first. In the measured temperature range DSC (Fig. S3 in $\mathrm{SI}$ ) reveals one $T_{g}$ in all composites, which for DR1 $(33, I)$ and DR1 $(40, h)$ is identical to the $T_{g}$ of the copolymer PMMA-co-DR1MA. In contrast, composite $\mathrm{NA}(33, \mathrm{~h})$ seems to have a higher $T_{g}$ compared to the pristine copolymer. These and other relevant parameters of the composites are summarized in Table 3. The films were freeze fractured and the fracture sites were examined using SEM (Fig. 3c-e). Evenly distributed bumps can be seen in all images. They are larger than an isolated single filler particle and are most probably small agglomerates covered with PDMS.

The tensile test data shows that the mechanical properties of the composites are dominated by the matrix (Fig. 4a). A slight bump in the elastic modulus at $100 \%$ strain is visible in all samples, which could be a sign of agglomerates being pulled apart or percolation being broken, as it is likely that the filler content employed in the composites is above the percolation threshold. The percolation threshold is normally no higher than 30 vol\%. ${ }^{35}$ The composite produced with short PDMS chains (composite DR1 $(33,1)$ ) has an initial elastic modulus $\left(Y_{\text {init }}\right)$ of $2.8 \mathrm{MPa}$, which rapidly decreases to $0.63 \mathrm{MPa}$ at high strains $\left(Y_{\text {end }}\right)$. It shows a strain at break $\left(\lambda_{\text {break }}\right)$ of $436 \%$ and a tensile strength $\left(\sigma_{\text {break }}\right)$ of $3.3 \mathrm{MPa}$. The other two composites which were produced with long PDMS chains (composite $\mathrm{DR} 1(40, \mathrm{~h})$ and $\mathrm{NA}(33, \mathrm{~h})$ ) show nearly identical properties, even though they have different filler contents. Both tensile curves in Fig. 4 nearly overlap. They have a $Y_{\text {init }}$ of $4.7 \mathrm{MPa}$ and 4.3 $\mathrm{MPa}$, respectively, and decreases to $Y_{\text {end }}=0.3 \mathrm{MPa}$ in a time frame similar to composite DR1(33,I). Their $\lambda_{\text {break }}$ are 641 $\%$ and $628 \%$, and their $\sigma_{\text {break }}$ are $2.92 \mathrm{MPa}$ and $2.84 \mathrm{MPa}$, respectively. The long chained PDMS is therefore effective in providing a slightly softer matrix, at least at strains above $50 \%$, and extending the maximum strain of the composite. The electrets can therefore in theory be operated at strains above $600 \%$.

Below strains of $50 \%$ the short chained PDMS is softer contrary to expectations, as shorter chains normally lead to a higher elastic modulus in elastomers. One reason is probably a higher concentration of crosslinker per PDMS chain ends for the shorter polymer, because the weight ratio of PDMS and crosslinker was kept constant in all composites. A higher 
crosslink density could well lead to an initially higher elastic modulus. Beyond that, factors other than purely the matrix, such as filler dispersion quality and size and its interaction with the matrix, can lead to complex mechanical behaviour.

Dynamic mechanical analysis (DMA) was also carried out to probe for frequency dependent viscoelasticity in the material (Fig. 4b). Maximum strain was limited to $2 \%$ by the testing setup, but the loss angle $\tan \delta$ nonetheless never rises above 0.25 in the investigated frequency range of $0.05 \mathrm{~Hz}$ to $10 \mathrm{~Hz}$, as is indicative of an elastic material. The elastic moduli differ from the values obtained by the tensile test due to different test parameters, but are still at the same position relative to each other and within the same range.
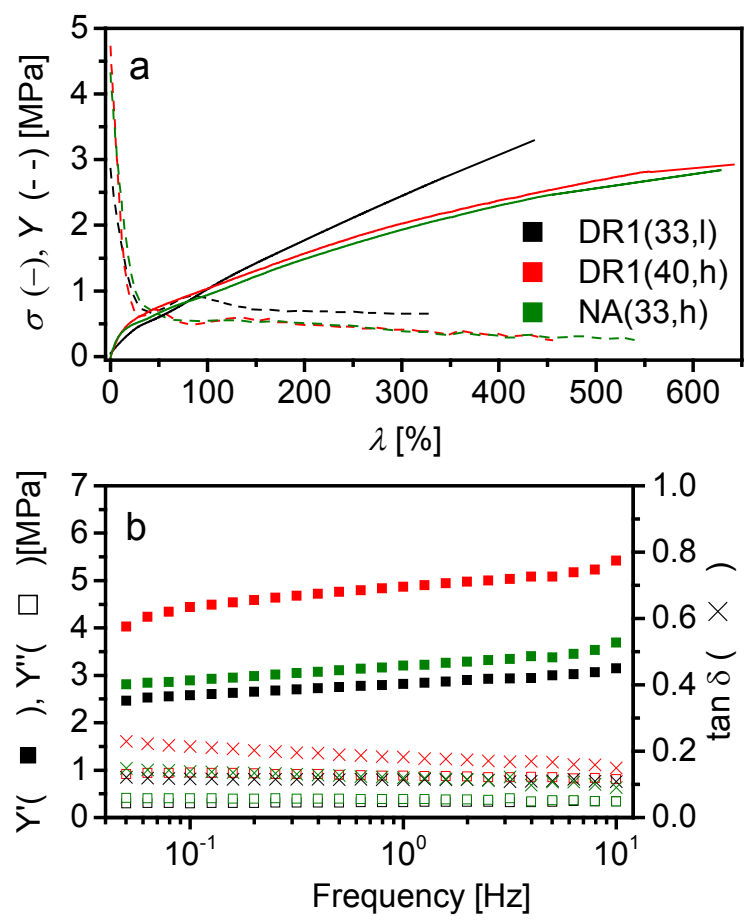

Fig. 4 (a) Tensile curve (solid line) and elastic modulus (dotted line) of the composites, plotting stress $(\sigma)$ and elastic modulus $(Y)$ against strain $(\lambda)$. (b) Storage modulus (filled squares), loss modulus (opens squares) and loss angle $\tan \delta$ (crosses) obtained by DMA of the composites.

Impedance spectroscopic measurements were also carried out for the composites and fitted with the HN equation (Fig. 5). The relaxation peaks are prominent in the imaginary part of the permittivity and can be matched to the relaxation of the respective copolymer fillers. Relaxations strengths of the composites were found to be 1.6 for composite DR1(33,I), 2.6 for composite DR1 $(40, h)$ and 2.3 for composite $N A(33, h)$. Though these values can seem radically diminished at first glance, they conform very well to approximate predictions made by continuous medium calculations, based on the HanaiBruggemann (HB) equation which is valid for filler concentrations between $20 \%$ and $50 \%{ }^{36}$

$\frac{\varepsilon_{c}-\varepsilon_{f}}{\varepsilon_{m}-\varepsilon_{f}}\left(\frac{\varepsilon_{m}}{\varepsilon_{c}}\right)^{1 / 3}=(1-f)$ where $\varepsilon_{\mathrm{c}}, \varepsilon_{\mathrm{f}}$ and $\varepsilon_{\mathrm{m}}$ are the permittivity of the composite, filler and matrix, respectively, and $f$ is the filler content. The relaxation strength is commonly used to estimate the lateral piezoelectric constant $\left(d_{31}\right)$ via the polarization obtained from equation (2) according to ${ }^{37-39}$

$d_{31}=P_{\text {Theo }}(1-2 v) \frac{1}{Y}+P_{\text {Theo }}(1-2 v) \frac{1}{Y} \frac{\left(\varepsilon_{\infty}-1\right)}{3}$

Where $v$ is the Poisson's ratio of the composite and $Y$ is the elastic modulus of the composite.

Table 3 Summary of tensile and electric properties of the composite.

\begin{tabular}{|c|c|c|c|c|}
\hline \multicolumn{2}{|c|}{ Composite } & DR1(33,I) & DR1 $(40, h)$ & $\mathrm{NA}(33, \mathrm{~h})$ \\
\hline$\Delta \varepsilon$ & $@ 140^{\circ} \mathrm{C}$ & 1.6 & 2.6 & 2.3 \\
\hline & $\mathrm{HB}$ & 2 & 2.7 & 2.5 \\
\hline$T_{g}$ & {$\left[{ }^{\circ} \mathrm{C}\right]$} & 126 & 125 & 116 \\
\hline
\end{tabular}

Tensile Properties

\begin{tabular}{lllll}
$Y_{\text {Init }}$ & {$[\mathrm{MPa}]$} & 2.8 & 4.7 & 4.3 \\
$Y_{\text {end }}$ & {$[\mathrm{MPa}]$} & 0.63 & 0.3 & 0.3 \\
$\lambda_{\text {break }}$ & {$[\%]$} & 436 & 641 & 628 \\
$\sigma_{\text {break }}$ & {$[\mathrm{MPa}]$} & 3.3 & 2.92 & 2.84 \\
\hline
\end{tabular}

Initial $d_{31}$, after $1 \mathrm{~h}$

\begin{tabular}{llccc}
$P_{\text {theo }}$ & {$\left[\mathrm{mC} \mathrm{m}^{-2}\right]$} & 0.42 & 0.69 & 0.58 \\
$d_{31, \text { theo }}$ & {$\left[\mathrm{pC} \mathrm{N}^{-1}\right]$} & 28 & 48 & 40 \\
$d_{31,50 \%}$ & {$\left[\mathrm{pC} \mathrm{N}^{-1}\right]$} & 33 & 46 & 46 \\
\hline
\end{tabular}

$d_{31}$, after $400 \mathrm{~h}$

\begin{tabular}{llccc}
$Q_{50 \%}$ & {$[\mathrm{nC}]$} & 0.26 & 0.61 & 0.17 \\
$Q_{150 \%}$ & {$[\mathrm{nC}]$} & 0.78 & 1.50 & 0.44 \\
$Q_{200 \%}$ & {$[\mathrm{nC}]$} & - & 1.80 & 0.56 \\
$d_{31,50 \%}$ & {$\left[\mathrm{pC} \mathrm{N}{ }^{-1}\right]$} & 4.6 & 8.9 & 4.0 \\
$d_{31,150 \%}$ & {$\left[\mathrm{pC} \mathrm{N}^{-1}\right]$} & 5.2 & 12.1 & 6.2 \\
$d_{31,200 \%}$ & {$\left[\mathrm{pC} \mathrm{N}^{-1}\right]$} & - & 10.1 & 7.0 \\
\hline
\end{tabular}

\section{$d_{31}$ after $4 \mathrm{~d}$ at $50^{\circ} \mathrm{C}$}

\begin{tabular}{llccc}
$Q_{50 \%}$ & {$[\mathrm{nC}]$} & 0.27 & 0.59 & 0 \\
$d_{31,50 \%}$ & {$\left[\mathrm{pC} \mathrm{N}{ }^{-1}\right]$} & 4.7 & 7.9 & 0 \\
\hline
\end{tabular}

Voltage, after $400 \mathrm{~h}$

\begin{tabular}{lcccc}
$U_{50 \%}$ & {$[\mathrm{~V}]$} & 0.27 & 1.1 & 0.36 \\
$U_{150 \%}$ & {$[\mathrm{~V}]$} & 0.55 & 2.4 & 0.84 \\
$U_{200 \%}$ & {$[\mathrm{~V}]$} & - & 2.7 & 1.05 \\
\hline
\end{tabular}

A simple mixing rule ${ }^{40}$ was used to estimate the composite $v$ to approximately 0.44 using the reported Poisson's ratios of PMMA and PDMS (0.33 and 0.5 respectively). ${ }^{41,42}$ For $Y$ the respective average in the range from 0 to $50 \%$ strain was taken. The calculated $d_{31}$ value was compared to the directly measured one (Table 3). 

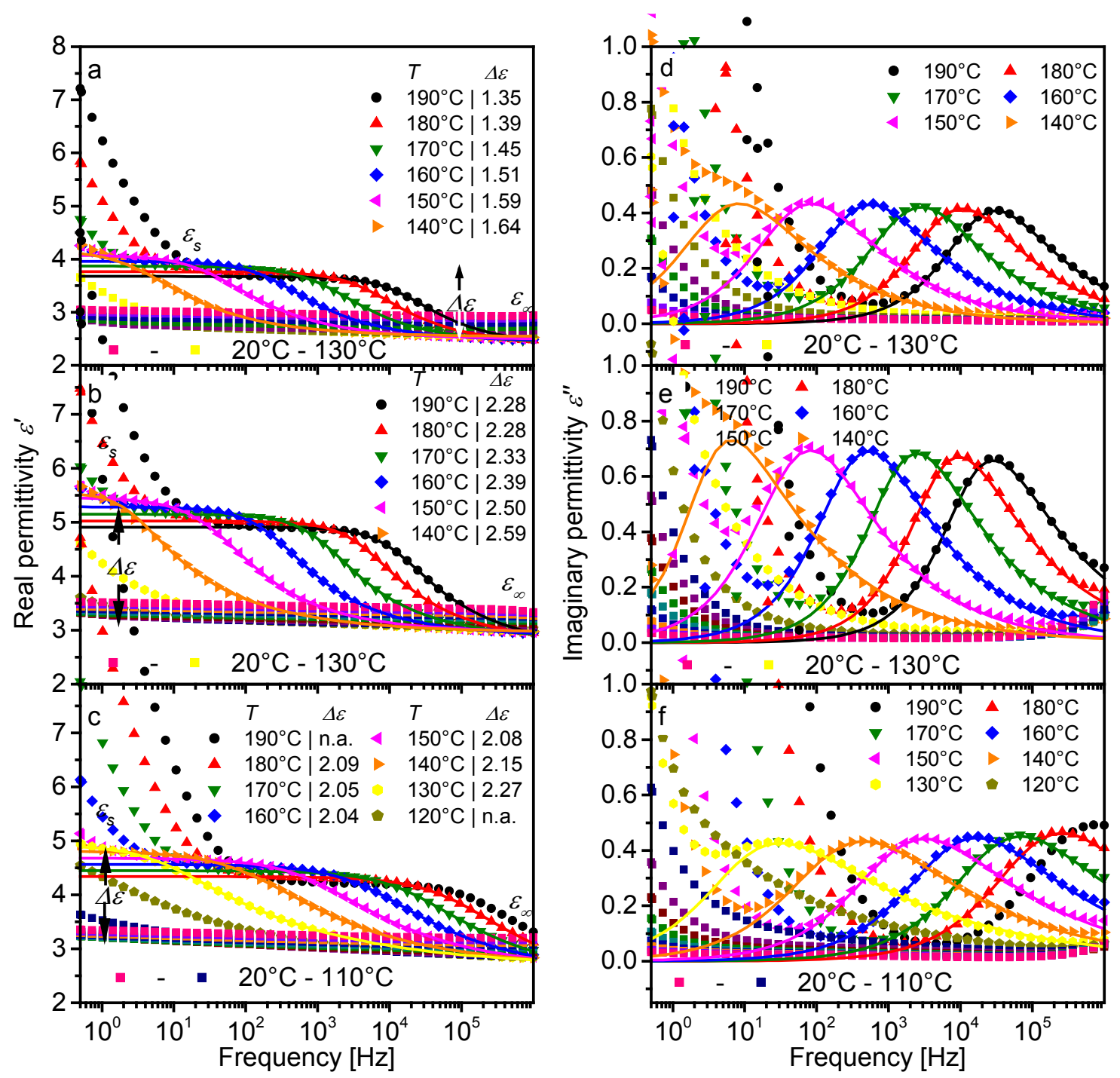

Fig. 5 Real permittivity of DR1(33,I) (a), DR1 $(44, h)(b)$ and $N A(33, h)(c)$, and the corresponding imaginary permittivity on the other side (d-f). The measurements are represented by dots; the HN-fit is represented by lines. The corresponding $\Delta \varepsilon$ is noted next to the temperature. (a) is reproduced with permission from reference 21 .

Equation (4) was primarily derived for monolithic piezoelectric electrets and a comparison to the measured value should reveal possible differences in the origin of piezoelectricity.

A few experiments were initially conducted to verify the validity of the piezoelectric coefficient measurements. For one, only an insignificant amount of current is collected when the composites are not poled, confirming the poled structure as source of the piezoelectric current. The composites were of course subsequently poled before their piezoelectricity was investigated. A polarity change experiment was conducted by inverting the connections to the composite. The resulting flip in the current sign reinforces this interpretation. The collected charge per cycle ( $Q_{x \%}$, where ${ }_{x \%}$ is the strain) can be calculated by integrating the current. The first test cycle consisted of straining the composite by $50 \%$ at $0.1 \mathrm{~Hz}$ (Fig. 6a). $d_{31}$ could then be calculated according to:

$d_{31}=\frac{Q * A_{c}}{F * A_{e}}$ where $Q$ is the charge collected per strain cycle, which was obtained by integrating the current, and $F$ is the force acting on the sample. $A_{c}$ and $A_{e}$ are the area of the sample cross section and the electrode respectively. The measured $d_{31}$ is quite near the value predicted by equation (4), which suggests that the mechanism of piezoelectricity is similar to bulk electrets. Specifically it assumes that the permanent dipole moment does not change significantly. Due to the use of a tensile testing machine for the piezoelectric measurements, incidental cyclic mechanical measurements were taken, though they are quite noisy. Representative curves can be seen in the SI (Fig. S7). A hysteresis is visible in all curves, as is the Mullins effect, but the average elastic modulus used in equation (4) remains unchanged and furthermore show, that the composites are mechanically stable over the course of hundreds and, in some cases, thousands of cycles. 


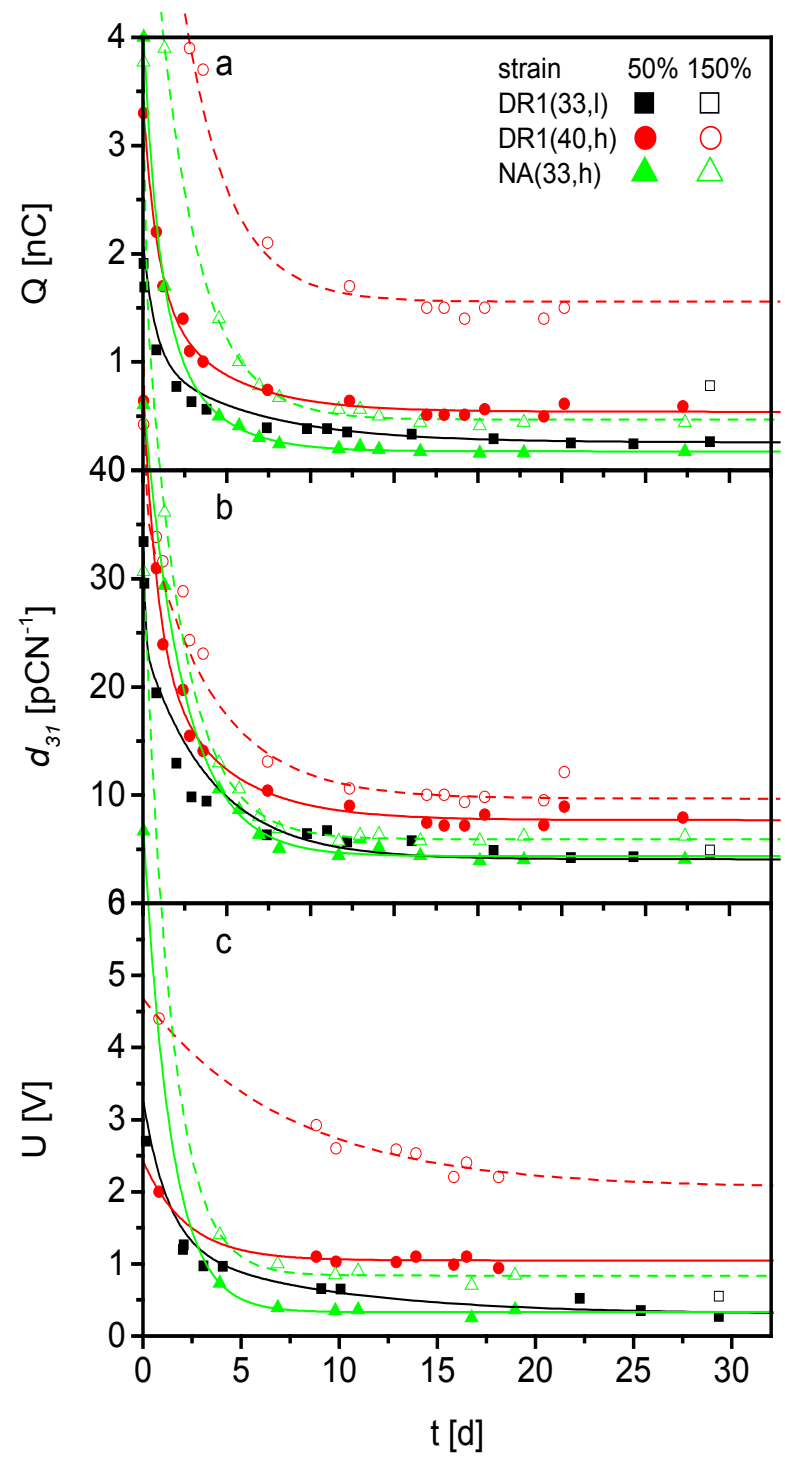

Fig. 6 Charge collected per cycle (a), the calculated $d_{31}$ coefficient (b) and the voltage generated per cycle over time (c) of the composites when strained to $50 \%$ (full symbols) and $150 \%$ (open symbols) over time. The patterned area represents the time the samples spent at $50^{\circ} \mathrm{C}$.

The electrets were periodically tested over a period of several weeks by straining them to $50 \%, 150 \%$ (Fig. 6a) and at the end to $200 \%$ (Table 3). The polarization seems to drop quite rapidly once the steel plate electrodes have been removed, until it reaches a stable value after two weeks. It has been shown, that the polarization is stable when the steel plates are not removed and a promising piezoelectric coefficient in the direction of poling $\left(d_{33}\right)$ of $26.7 \mathrm{pC} \mathrm{N}{ }^{-1}$ was measured for the poled material. ${ }^{23}$ This suggests that the relaxation is due to liberation of stabilizing charges on the electrodes which are removed, or between agglomerates which are broken up when the composite is strained. Most probably a mixture of both is at work. Experiments are currently underway to shed more light on this issue. Composite DR1 $(33,1)$ was only strained to $150 \%$ once at the end and ruptured when a strain of $200 \%$ was attempted. For composites DR1 $(40, h)$ and NA(33,h), $200 \%$ could easily be reached. Accordingly, on average $d_{31}$ values ofaround 5, 10 and $6 \mathrm{pC} \mathrm{N} \mathrm{N}^{-1}$ could be reached for composites $\operatorname{DR} 1(33, \mathrm{l}), \mathrm{DR} 1(40, \mathrm{~h})$ and $\mathrm{NA}(33, \mathrm{~h})$ respectively.

Table 3 nicely illustrates that the charge collected per strain cycle is linearly dependent on the strain. It also shows a slightly larger $d_{31}$ at higher strains (Fig. 6b), because the relevant $Y$ region has become much softer. This showcases how the $d_{31}$ value alone insufficiently describes the piezoelectric properties of this material. The values compare nonetheless quite favorably to commercially used ferroelectric polymers, such as PVDF with $d_{31}$ between 6 and $20 \mathrm{pC} \mathrm{N}{ }^{-1}$, with the obvious caveat that PVDF cannot be strained to $200 \%$ and possibly beyond.

The frequency dependence and the long term stability under cyclic mechanical load were also investigated. As can be seen in Fig. 7a, the charge collected per cycle is not significantly different for frequencies between $1 \mathrm{~Hz}$ and $0.1 \mathrm{~Hz}$ in all composites. The response above $1 \mathrm{~Hz}$ would have been interesting, but unfortunately $1 \mathrm{~Hz}$ was the upper frequency limit of the tensile testing machine. It can also be seen (Fig. $7 b$ ), that the current does not significantly drop over a period of $5 \mathrm{~h}$ when strained at a frequency of $0.5 \mathrm{~Hz}$ once it has stabilized.

The electrets were at the end subjected to elevated temperatures (Table 3 ). At $50{ }^{\circ} \mathrm{C}$, both composite DR1(33,I) and DR1 $(40, \mathrm{~h})$ were stable and maintained their $d_{31}$ over at least 4 days. The $d_{31}$ of composite $\mathrm{NA}(33, \mathrm{~h})$ dropped to 2.5 $\mathrm{pCN}^{-1}$ after one day at $50^{\circ} \mathrm{C}$ and to zero after two. Newly poled samples of all three films showed the same stability behavior.

The voltage generated per cycle $\left(U_{x \%}\right.$, where ${ }_{x \%}$ is the strain) (Fig. 6c) shows a similar decay as $Q_{x \%}$ over the course of several weeks. The maximum stable voltage, $2.5 \mathrm{~V}$, was generated by straining composite DR $1(40, \mathrm{~h})$ to $200 \%$, while typical voltage values for the other two composites were well below $1 \mathrm{~V}$. The best voltage per cycle is comparable to the nanocomposite generator containing PMN-PT particles mentioned in the introduction, ${ }^{18}$ though the currents produced by the nanocomposite are much larger than those presented here, which is an indication for larger $d_{31}$ values in ceramics based composites. Unfortunately no charges were reported, making direct comparisons difficult, as currents are dependent on the deformation speed.

It was noted before that PMMA-Co-NAMA has a rather low $T_{g}$ and it was expected that composite $N A(33, h)$ should be more inclined to relax. Indeed all the data point towards this being the case, even though the PDMS matrix seems to have stabilizing effect on the particles, as seen in the slightly higher 


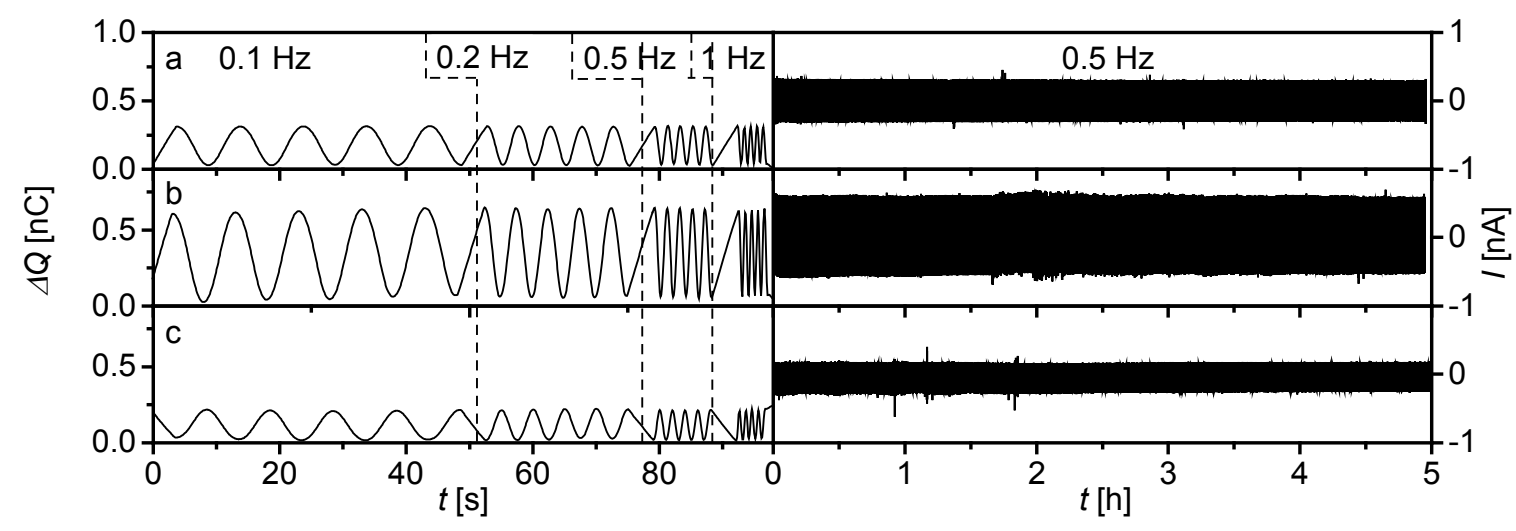

Fig. 7 Frequency dependence of the charge collected per cycle (left graph) and current response over 5 hours at $0.5 \mathrm{~Hz}$ (right graph) of DR1(33,I) (a), $\operatorname{DR} 1(44, h)(b)$ and $N A(33, h)(c)$.

composite $T_{g}$. The collected charge per cycle of composite $\mathrm{NA}(33, \mathrm{~h})$ decays much faster than the other two composites and collects less than composite DR1(33,l) once stable after $400 \mathrm{~h}$, this in spite of the higher theoretical polarization. It has a higher $d_{31}$ than composite $\operatorname{DR} 1(33,1)$, which is attributed to its lower elastic modulus. The decay of the generated voltage follows a similar trend. In addition, exposure to temperatures of $50{ }^{\circ} \mathrm{C}$ and above totally depolarizes the composite. It must therefore be concluded, that the $T_{g}$ of the copolymer is too low and renders the composite unsuitable for most applications.

On the other hand PMMA-Co-DR1MA seems to be stable up to $50{ }^{\circ} \mathrm{C}$. Further information can be gleamed by comparing the two composites in which PMMA-co-DR1MA was incorporated. From the impedance spectra one can estimate a 1.6 times larger polarization for composite $\mathrm{DR} 1(40, \mathrm{~h})$ compared to DR1 $(33, I)$ which should lead to a similar ratio in the charge collected per cycle. This is true right after the composites have been poled and after they have relaxed. It can be speculated, that both matrices have similar effects on the relaxation of the polarization, which is not surprising, as both are PDMS with only different molecular weights.

\section{Experimental sections}

\section{Materials}

All chemicals were purchased from Sigma Aldrich and used as received. Hydroxyl end-terminated PDMS (AB116665, $M_{w}=$ $139^{\prime} 000 \mathrm{~g} \mathrm{~mol}^{-1}$ ) and ethyltriacetoxy silane crosslinker (XL) were purchased from $A B C R$. Solvents were purified and dried by standard procedures. PMMA-co-DR1MA(50\%) $)^{23}$ and the high molecular weight $\left(M_{w}=692^{\prime} 000 \mathrm{~g} \mathrm{~mol}^{-1}\right)$ hydroxyl endterminated $\mathrm{PDMS}^{43}$ were synthesized according to literature.

\section{Synthesis of PMMA-co-NAMA}

An overview of the synthesis of PMMA-Co-NAMA can be seen in Scheme $\mathrm{S} 1$ in the SI. Methacrylate functionalized nitroaniline derivate (NAMA) is prepared by starting from 1fluoro-4-nitrobenzene (1) and 2-methylaminoethanol to yield 2-methyl(4-nitrophenyl)amine)ethanol (2), which allowed the methacrylate functionality to be attached using methacryloyl chloride, to yield NAMA (3). PMMA-Co-NAMA was prepared by free radical copolymerization of methyl methacrylate and NAMA.

\section{Synthesis of 2-methyl(4-nitrophenyl)amine)ethanol (2)}

1-Fluoro-4-nitrobenzene $(24.9 \mathrm{~g}, 0.18 \mathrm{~mol})$ and 2methylaminoethanol $(25 \mathrm{~g}, 0.33 \mathrm{~mol})$ were added to an icecooled suspension of $\mathrm{K}_{2} \mathrm{CO}_{3}(36.8 \mathrm{~g}, 0.27 \mathrm{~mol})$ in THF (35 g). After stirring for $5 \mathrm{~min}$ the ice bath was removed and the solution refluxed at $45{ }^{\circ} \mathrm{C}$ for $18 \mathrm{~h}$. It was then washed with brine and extracted with THF. 2-methyl(4nitrophenyl)amine)ethanol was obtained by removing the THF in a rotary evaporator and drying at high vacuum for $24 \mathrm{~h}$ (84 $\%$ yield).

${ }^{1} \mathrm{H}$ NMR $\left(400 \mathrm{MHz}, \mathrm{CDCl}_{3}, \delta\right): 1.99\left(\mathrm{t}, 1 \mathrm{H},{ }^{3} \mathrm{~J}=5.36 \mathrm{~Hz}, \mathrm{OH}\right), 3.16$ $\left(\mathrm{s}, 3 \mathrm{H}, \mathrm{NCH}_{3}\right), 3.65\left(\mathrm{t}, 2 \mathrm{H},{ }^{3} \mathrm{~J}=5.6 \mathrm{~Hz}, \mathrm{NCH}_{2} \mathrm{CH}_{2}\right), 3.89\left(\mathrm{q}, 2 \mathrm{H},{ }^{3} \mathrm{~J}\right.$ $\left.=5.4 \mathrm{~Hz}, \mathrm{CH}_{2} \mathrm{CH}_{2} \mathrm{OH}\right), 6.66\left(\mathrm{~d}, 2 \mathrm{H},{ }^{3} \mathrm{~J}=9.4 \mathrm{~Hz}\right.$, Ar- $\mathrm{H}$ ortho to $\mathrm{NO}_{2}$ ), $8.06\left(\mathrm{~d}, 2 \mathrm{H},{ }^{3} \mathrm{~J}=9.2 \mathrm{~Hz} \mathrm{Ar}-\mathrm{H}\right.$ meta to $\mathrm{NO}_{2}$ ) (Fig. S8 in the $\mathrm{SI})$.

${ }^{13} \mathrm{C}$ NMR $\left(100 \mathrm{MHz}, \mathrm{CDCl}_{3}, \delta\right): 39.4\left(\mathrm{NCH}_{3}\right), 54.5\left(\mathrm{CH}_{2} \mathrm{CH}_{2} \mathrm{OH}\right)$, $60.1\left(\mathrm{NCH}_{2} \mathrm{CH}_{2}\right), 110.4\left(\mathrm{C}(\mathrm{Ar})\right.$ meta to $\left.\mathrm{NO}_{2}\right), 126.2$ (C(Ar) ortho to $\left.\mathrm{NO}_{2}\right), 136.9\left(\mathrm{C}(\mathrm{Ar}) \mathrm{NO}_{2}\right), 153.9\left(\mathrm{NC}(\mathrm{Ar})\right.$ para to $\mathrm{NO}_{2}$ ) (Fig. S9 in the $\mathrm{SI}$ ).

\section{Synthesis of NAMA (3)}

Freshly distilled methacryloyl cholride $(1.65 \mathrm{~g}, 16 \mathrm{mmol})$ was slowly added dorpwise to an ice-cooled solution of 2-methyl(4nitrophenyl)amine)ethanol (3 $\mathrm{g}, 15 \mathrm{mmol}$ ) and distilled triethylamine $(1.59 \mathrm{~g}, 16 \mathrm{mmol})$ in dry dichloromethane $(65$ $\mathrm{ml}$ ) under argon atmosphere. The ice bath was removed an hour after the methacryloyl chloride was added and the solution was left to react overnight. The reaction mixture was washed with aqueous $\mathrm{NaHSO}_{4}$. NAMA was isolated by column chromatography (Ethyl Acetate $20 \%$, Hexane $80 \%$ ) to give a yield of $81 \%$ after drying at high vacuum for $18 \mathrm{~h}$. The reaction was carried out multiple times to obtain enough starting material for the polymerization.

${ }^{1} \mathrm{H}$ NMR $\left(400 \mathrm{MHz}_{\mathrm{CDCl}}, \delta\right): 1.90\left(\mathrm{~s}, 3 \mathrm{H}, \mathrm{CCH}_{3}\right), 3.14(\mathrm{~s}, 3 \mathrm{H}$, $\left.\mathrm{NCH}_{3}\right), 3.78\left(\mathrm{t}, 2 \mathrm{H},{ }^{3} \mathrm{~J}=5.7 \mathrm{~Hz}, \mathrm{NCH}_{2} \mathrm{CH}_{2}\right), 4.37\left(\mathrm{t}, 2 \mathrm{H},{ }^{3} \mathrm{~J}=5.8\right.$ $\mathrm{Hz}, \mathrm{CH}_{2} \mathrm{CH}_{2} \mathrm{OC}$ ), 5.57 (s, $\left.1 \mathrm{H}, \boldsymbol{H C H C C H}_{3}\right), 6.05$ (s, $1 \mathrm{H}, \mathrm{HCHCCH}_{3}$ ), 
$6.69\left(\mathrm{~d}, 2 \mathrm{H},{ }^{3} \mathrm{~J}=9.3 \mathrm{~Hz}, \mathrm{Ar}-\mathrm{H}\right.$ meta to $\left.\mathrm{NO}_{2}\right), 8.11\left(\mathrm{~d}, 2 \mathrm{H},{ }^{3} \mathrm{~J}=9.3\right.$ $\mathrm{Hz}, \mathrm{Ar}-\mathrm{H}$ ortho to $\mathrm{NO}_{2}$ ) (Fig. S10 in the SI).

${ }^{13} \mathrm{C}$ NMR $\left(100 \mathrm{MHz} \mathrm{CDCl}_{3}, \delta\right):{ }^{13} \mathrm{C} \mathrm{NMR}\left(100 \mathrm{MHz} \mathrm{CDCl}_{3}, \delta\right)$ : $18.3\left(\mathrm{CCH}_{3}\right), 39.0\left(\mathrm{NCH}_{3}\right), 50.8\left(\mathrm{CH}_{2} \mathrm{CH}_{2} \mathrm{O}\right), 61.4\left(\mathrm{NCH}_{2} \mathrm{CH}_{2}\right)$, 110.5 (C(Ar) meta to $\left.\mathrm{NO}_{2}\right), 126.2$ (C(Ar) ortho to $\left.\mathrm{NO}_{2}\right), 126.3$ $\left(\mathrm{CH}_{2} \mathrm{CCH}_{3}\right), 135.7\left(\mathrm{CH}_{2} \mathrm{CCH}_{3}\right), 137.4\left(\mathrm{CNO}_{2}\right), 153.4$ ( $\mathrm{NC}(\mathrm{Ar})$ para to $\left.\mathrm{NO}_{2}\right), 167.2(\mathrm{OC}=\mathrm{O})$ (Fig. S11 in the $\mathrm{SI}$ ).

\section{Synthesis of PMMA-co-NAMA}

NAMA (5 g, $19 \mathrm{mmol}$ ) was added to a $50 \mathrm{ml}$ schlenk-flask which was thoroughly dried under vacuum with the help of a heat-gun. The flask was flooded with argon. Azobisisobutyronitrile (AIBN) (33 mg, $0.2 \mathrm{mmol}$ ) was added and then capped with a septum trough which $\mathrm{N}, \mathrm{N}$ dimethylformamide $(10 \mathrm{ml})$ and MMA $(1.2 \mathrm{ml})$ were inserted via syringe. The solution was then rigorously bubbled with argon for 30 minutes followed by three freeze-pump-thawcycles. The reaction was started afterwards by heating the solution to $90{ }^{\circ} \mathrm{C}$ and proceeded overnight. It was terminated by bringing the solution to room temperature, adding the same amount of DMF as already in the solution and precipitating the solution into 5 times the amount of methanol. The copolymer was collected using a $0.45 \mu \mathrm{m}$ poresize Nylon membrane filter, rinsed with methanol on the filter and dried.

${ }^{1} \mathrm{H}$ NMR (400 MHz, $\mathrm{CDCl}_{3}, \delta$ ): 0.5-2.10 (m, 5H, backbone), 3.20 (b, $\left.3 \mathrm{H}, \mathrm{NCH}_{3}\right), 3.89$ (b, $\left.2 \mathrm{H}, \mathrm{NCH}_{2} \mathrm{CH}_{2}\right), 4.17\left(\mathrm{~m}, 2 \mathrm{H}, \mathrm{CH}_{2} \mathrm{CH}_{2} \mathrm{OC}\right)$, $6.93\left(\mathrm{~b}, 2 \mathrm{H}, \mathrm{Ar}-\mathrm{H}\right.$ meta to $\left.\mathrm{NO}_{2}\right), 8.13(\mathrm{~m}, 2 \mathrm{H}, \mathrm{Ar}-\mathrm{H}$ ortho to $\mathrm{NO}_{2}$ ) (Fig. $\mathrm{S} 1$ in the $\mathrm{SI}$ ).

${ }^{13} \mathrm{C}$ NMR $\left(100 \mathrm{MHz}, \mathrm{CDCl}_{3}, \delta\right): 16.5-18.6\left(\mathrm{CCH}_{3}\right), 38.5\left(\mathrm{NCH}_{3}\right)$, $44.3-44.7\left(\mathrm{CCH}_{3}\right), 49.9\left(\mathrm{OCH}_{3}\right), 51.5\left(\mathrm{CCH}_{2} \mathrm{C}\right), 53.8\left(\mathrm{CH}_{2} \mathrm{CH}_{2} \mathrm{O}\right)$, $62.6\left(\mathrm{NCH}_{2} \mathrm{CH}_{2}\right), 111.1$ (C(Ar) meta to $\left.\mathrm{NO}_{2}\right), 125.9$ (C(Ar) ortho to $\left.\mathrm{NO}_{2}\right), 136.6\left(\mathrm{C}(\mathrm{Ar}) \mathrm{NO}_{2}\right), 154.1\left(\mathrm{NC}(\mathrm{Ar})\right.$ para to $\left.\mathrm{NO}_{2}\right), 176.2-$ 177.5 (OC=O) (Fig. S2 in the SI).

\section{Nanoprecipitation of copolymers}

Recent developments in nanoprecipitation show that in theory any kind of polymer can be obtained in particle form. ${ }^{44}$ This was accomplished for both types of copolymers, PMMA-coDR1MA and PMMA-co-NAMA. A copolymer solution $(4 \mathrm{~g} / \mathrm{l})$ in DMF was added dropwise to stirred deionised water. The particles settled over night and were collected using a $0.45 \mu \mathrm{m}$ pore-size Nylon membrane filter, rinsed with water on the filter and dried at high vacuum for several days. Particles with around $60 \mathrm{~nm}$ diameter were obtained for both.

\section{Composite production}

To produce composites, the particles were first dispersed into cyclohexane via tip sonication, (Sonics Vibra-cell VCX 750 at 40 $\%$ power output) while immersed in an ice bath for $20 \mathrm{~min}$. After the particles have been dispersed, hydroxyl-terminated PDMS and ethyltriacetoxy silane crosslinker ${ }^{45,23}$ (100 $\mu \mathrm{l}$ per $\mathrm{g}$ PDMS) were added to obtain a pre-composite solution with a set weight ratio (Table 2) of particles to PDMS. A homogeneous dispersion was formed after stirring overnight, at which point titanium 2-ethylhexoxide catalyst $(<10 \mu \mathrm{l}$ per $\mathrm{g}$ PDMS) was added and films were then produced by blade casting using a Zehntner ZUA 2000. The films were drawn on Teflon coated glass plates. All samples were first dried in air over night to complete the crosslink reaction and then placed in a vacuum oven at $0.1 \mathrm{mbar}$ and $130{ }^{\circ} \mathrm{C}$ for at least $8 \mathrm{~h}$ to remove residual cyclohexane to obtain free standing films typically $40 \mu \mathrm{m}$ thick.

\section{Standard measurement methods}

NMR spectra were recorded on a Bruker Avance-400 spectrometer (400 MHz at room temperature). Gel permeation chromatography (GPC) measurements in tetrahydrofuran eluent were done with an Agilent 1100/PSS WinGPC 8.1 system calibrated with PMMA standards (Polymer Standards Service). Two columns (100, $1000 \AA$ A pore size SDVGel) and a flow rate of $1 \mathrm{ml} \mathrm{min}{ }^{-1}$ were used. Signals were detected with a UV and IR detector. DSC measurements were performed on a Perkin Elmer DSC 8000 . The DSC cycle consisted of two heating steps from $20{ }^{\circ} \mathrm{C}$ to $200{ }^{\circ} \mathrm{C}$ and a cooling step from $200{ }^{\circ} \mathrm{C}$ to $20{ }^{\circ} \mathrm{C}$ at a rate of $20{ }^{\circ} \mathrm{C} \mathrm{min}{ }^{-1}$. Tensile tests were carried out on a Zwick Z010 tensile testing machine with standard dog bone-shaped samples punched out from the composite films. The elongation was measured with the crosshead position while the deformation speed was 200 $\mathrm{mm} \mathrm{min}^{-1}$. The results are averaged from five independent measurements. Scanning electron microscopy (SEM) images were taken on a FEI NovaNanoSEM 230 in secondary electron mode using a through lens detector at $10-15 \mathrm{kV}$ acceleration voltage. The particle size in SEM images was determined by measuring the diameter of 50 neighboring particles in a representative area. Dynamic light scattering (DLS) was done with a Malvern Zetasizer Nano ZS, where the results were averaged from 3 separate measurements. Measurements were usually done directly after nanoprecipitation and were diluted with water to approximately $0.01 \mathrm{wt} \%$ copolymers in PMMA cuvettes. Dynamic mechanical analysis was carried out on a RSA 3 DMA from TA Instruments. Stripes of $10 \mathrm{~mm} \times 20$ $\mathrm{mm}$ were measured under a dynamic load of $4 \mathrm{~g}$, at $2 \%$ strain in the frequency range of $0.05-10 \mathrm{~Hz}$.

\section{Impedance spectroscopy}

For the temperature dependent impedance spectroscopic measurements, a Novocontrol high impedance Alpha Analyzer was used with the standard BDS 1200 sample cell and Quatro Cryosystem temperature controler. The copolymers were prepressed to $25 \mathrm{mg}$ pellets which were heated to $185^{\circ} \mathrm{C}$ and compressed between two metal electrodes with three $100 \mu \mathrm{m}$ glass fibers as spacer in between. The final thickness of the samples was verified with a Heidenhain thickness measuring gauge. The composites were measured by sputtering gold electrodes with $2 \mathrm{~cm}$ diameter on either side of a free standing film, improving the contact to the metal electrodes in the sample cell. The thickness was measured with the thickness measuring gauge. Impedance spectra were obtained at selected intervals between $20{ }^{\circ} \mathrm{C}$ to $190{ }^{\circ} \mathrm{C}$ from $0.5 \mathrm{~Hz}$ to 1 $\mathrm{MHz}$.

\section{Poling}

The composites, sandwiched between two $15 \mathrm{~mm}$ diameter circular steel discs acting as electrodes, were poled with 30 $\mathrm{V} \mu \mathrm{m}^{-1}$ at $120{ }^{\circ} \mathrm{C}$ for $10 \mathrm{~min}$ and afterwards cooled to RT with 
the field still on, at a rate of $-4{ }^{\circ} \mathrm{C} \mathrm{min}^{-1}$. The field was maintained by a Stanford Research Systems PS350 high voltage source. Temperature control was facilitated by a Lauda RC6 CP thermostatic oil bath connected to a closed glass container which housed the composite. The choice of the poling temperature was guided by studies showing the ideal poling temperature being slightly below $T_{g}{ }^{28}$

\section{Piezoelectric coefficient $\left(d_{31}\right)$ measurements}

Close up pictures and a schematic representation of the testing setup can be seen in Fig. S12 and S13 in the SI. A Zwick Z010 tensile testing machine was used to strain and measure the force on the electrets. The metallic clamps of the tensile testing machine were covered with a layer of adhesive tape to electrically isolate them from the sample. A strip of adhesive copper tape was fixed on both the upper and lower clamp. Both sides of the poled area of the electrets were covered with carbon black powder. A connective strip, going from the poled area to the sample edge, was applied on each side, facing opposite edges. When placed in the tensile testing machine, the copper tape contacted the carbon black and a Keithley 2000 recorded the current passed through a Stanford Research Systems SR570 low noise current preamplifier while the sample was cyclically strained.

\section{Conclusions}

It has been shown, that the method used to produce organic composite-electrets can be in principle extended to NLOpolymers other than PMMA-co-DR1MA, and that the properties can be improved with an optimized matrix. The charge collected per cycle initially decreases until it reaches a stable value after around one week and the nature of this relaxation has to be better understood in order to counteract it. While composites with PMMA-co-DR1MA can retain their performance at temperatures up to $50{ }^{\circ} \mathrm{C}$, the composite with PMMA-Co-NAMA depolarized at $50{ }^{\circ} \mathrm{C}$, probably due to its low $T_{g}$. The piezoelectric performance of all composites are comparable to common ferroelectric electrets, but can in addition operate at $200 \%$ strain and theoretically, according to the tensile tests, up to $600 \%$. NLO polymers with higher $T_{g}$ can be used in the future to produce more stable poled structures with specific electromechanical properties. The presented elastic piezoelectrets will probably find applications in the many fields in which piezoelectric materials with such high strains are sought for, most immediately in energy harvesting, but also as components in soft electronics or as sensors and transducers.

\section{Acknowledgements}

We gratefully acknowledge the Swiss National Science Foundation (200021L_140577/1 and 206021_150638/1) and the Swiss Federal Laboratories for Materials Science and Technology Empa for financial support. We are also thankful of the help of T. D'Anna in producing the nanoparticles. Furthermore, we would like to thank Prof. D. Damjanovic from the EPFL for his invaluable advice, Dr. R.
Brönnimann for his kind support with the electric measurements, B. Fischer for the DSC measurements, $P$ Caspari for helping with the DMA measurements, Dr. F. Clemens for his support and insightful discussions, and Dr. M. Dascalu for the high $M_{w}$ PDMS (all Empa). We are also indebted to Prof. S. Bauer from the University of Linz for his useful input.

\section{Author Contributions}

Y.S.K. performed the synthesis and the characterization of all materials and wrote the manuscript together with D.M.O with input from all authors. D.M.O. initiated the activity for elastic polable composites, designed the materials, and coordinated this research. All authors contributed with discussions and have given approval to the final version of the manuscript.

\section{References}

1 G. M. Sessler, J. Acoust. Soc. Am., 1963, 35, 1354.

2 M. A. Parada and A. de Almeida, Nucl. Instruments Methods Phys. Res. Sect. B Beam Interact. with Mater. Atoms, 2002, 191, 820.

3 J. E. West, in 6th International Symposium on Electrets,(ISE 6) Proceedings., 1988, 209.

4 B. Stadlober, M. Zirkl, G. Leising, N. Gaar, I. Graz, S. BauerGogonea and S. Bauer, IEEE Trans. Dielectr. Electr. Insul., 2006, 13, 1087.

5 V. Kestelman, L. Pinchuk and V. Goldade, Electrets In Engineering, Springer, Berlin, 2000.

6 R. Gerhard-Multhaupt, IEEE Trans. Electr. Insul., 1987, 22, 531.

7 B. P. Mahale, D. Bodas and S. A. Gangal, in 2011 6th IEEE International Conference on Nano/Micro Engineered and Molecular Systems, 2011, 658.

8 F. S. Foster, K. A. Harasiewicz and M. D. Sherar, IEEE Trans. Ultrason. Ferroelectr. Freq. Control, 2000, 47, 1363.

9 H. R. Gallantree, IEEE Proc. I Solid State Electron Devices, 1983, 130, 219.

10 M. G. Broadhurst and G. T. Davis, in Electrets, Springer, Berlin, 1980.

11 T. Q. Trung and N.-E. Lee, Adv. Mater., 2016, 28, 4338.

12 X. Li, R. Zhang, W. Yu, K. Wang, J. Wei, D. Wu, A. Cao, Z. Li, Y. Cheng, Q. Zheng, R. S. Ruoff and H. Zhu, Sci. Rep., 2012, 2, 870.

13 B. C.-K. Tee, A. Chortos, A. Berndt, A. K. Nguyen, A. Tom, A. McGuire, Z. C. Lin, K. Tien, W.-G. Bae, H. Wang, P. Mei, H.-H. Chou, B. Cui, K. Deisseroth, T. N. Ng and Z. Bao, Science, 2015, 350, 313.

14 G.-T. Hwang, M. Byun, C. K. Jeong and K. J. Lee, Adv. Healthc. Mater., 2015, 4, 646.

15 S. Park, H. Kim, M. Vosgueritchian, S. Cheon, H. Kim, J. H. Koo, T. R. Kim, S. Lee, G. Schwartz, H. Chang and Z. Bao, Adv. Mater., 2014, 26, 7324.

16 W. Meier and H. Finkelmann, Macromolecules, 1993, 26, 1811.

17 D. Khastgir and K. Adachi, J. Polym. Sci. Part B Polym. Phys., 1999, 37, 3065.

18 C. K. Jeong, J. Lee, S. Han, J. Ryu, G.-T. Hwang, D. Y. Park, J. H. Park, S. S. Lee, M. Byun, S. H. Ko and K. J. Lee, Adv. Mater., 2015, 27, 2866.

19 Z. Zhang, C. Yao, Y. Yu, Z. Hong, M. Zhi and X. Wang, Adv. Funct. Mater., 2016, 26, 6760.

20 J. W. Tsai, J. J. Wang and Y. C. Su, Sensors Actuators, A Phys., 2014, 215, 176

21 C. Ohm, M. Brehmer, R. Zentel, Adv. Polym. Sci., 2012, 250, 49. 
22 P. Papadopoulos, P. Heinze, H. Finkelmann, F. Kremer, Macromolecules, 2010, 43, 6666.

23 Y. S. Ko, F. A. Nüesch, D. Damjanovic and D. M. Opris, Adv. Mater., 2017, 29, 1603813.

24 P. N. Prasad and B. A. Reinhardt, Chem. Mater., 1990, 2, 660.

25 A. Nahata, J. Shan, J. T. Yardley and C. Wu, J. Opt. Soc. Am. B, 1993, 10, 1553.

26 A. L. McClellan, in Tables of Experimental Dipole Moments, W.H. Freeman and Company, San Francisco, 1963.

27 W. M. Haynes, in CRC Handbook of Chemistry and Physics, Taylor \& Francis, New York, 2015.

28 D. M. Burland, R. D. Miller and C. A. Walsh, Chem. Rev., 1994, 94, 31.

29 S. Bauer, S. Bauer-Gogonea, B. Ploss and B. Ploss, J. Non. Cryst. Solids, 2005, 351, 2759.

30 S. Havriliak and S. Negami, Polymer, 1967, 8, 161.

31 Y. Seki, R. Kita, N. Shinyashiki, S. Yagihara and M. Yoneyama, AIP Conf. Proc., 2013, 469, 466.

32 Z.-Y. Cheng, S. Yilmaz, W. Wirges, S. Bauer-Gogonea and S. Bauer, J. Appl. Phys., 1998, 83, 7799.

33 W. Ren, S. Bauer, S. Yilmaz, W. Wirges and R. GerhardMulthaupt, J. Appl. Phys., 1994, 75, 7211.

34 L. Onsager, J. Am. Chem. Soc., 1936, 58, 1486.

35 X. Yang, J. Hu, S. Chen, J. He, Sci. Rep., 2016, 6, 30597.

36 T. Hanai, Kolloid-Zeitschrift, 1960, 171, 23.

37 J. S. Harrison and Z. Ounaies, in Encyclopedia of Polymer Science and Technology, Wiley, Hoboken, 2002.

38 H. Stefanou, J. Appl. Phys., 1979, 50, 1486.

39 K. S. Ramadan, D. Sameoto and S. Evoy, Smart Mater. Struct., 2014, 23, 33001.

40 P. R. Marur, Mat. Let., 2004, 58, 3971.

41 G. Geertz, J. Wieser, I. Alig, G. Heinrich, Pol. Eng. Sci., 2016, 47, 21.

42 C. M. Harris, in Shock and Vibration Handbook, McGraw-Hill, New York, 1977.

43 J. E. Q. Quinsaat, M. Alexandru, F. A. Nüesch, H. Hofmann, A Borgschulte and D. M. Opris, J. Mater. Chem. A, 2015, 3, 14675.

44 S. Schubert, J. T. Delaney, Jr and U. S. Schubert, Soft Matter, 2011, 7, 1581.

45 D. M. Opris, M. Molberg, C. Walder, Y. S. Ko, B. Fischer and F. A. Nüesch, Adv. Funct. Mater., 2011, 21, 3531. 